\title{
sciendo
}

DOI: $10.2478 /$ abcsj-2019-0020

American, British and Canadian Studies, Volume 33, December 2019

\section{Icebound Modernity: The Shipwreck as Metaphor in Dan Simmons' The Terror}

\author{
ADAM LOVASZ \\ Eötvös Loránd University, Budapest, Hungary
}

\begin{abstract}
In this article, I seek to present a "metaphorology" of the shipwreck through a literary example. As Hans Blumenberg has noted, the shipwreck has served as a metaphor for the contingency of human existence in Western culture. Building on Blumenberg's ideas, I argue that modernity heightens contingency and destroys the possibility of a coherent, anthropocentric discourse. For Quentin Meillassoux, the modern outlook exposes the contingency and inhumanity of reality. Building on Meillassoux and Blumenberg's work, I address ideas pertaining to contingency and the metaphor of modernity-as-shipwreck by engaging with Dan Simmons' historical novel, The Terror (2007), based on events surrounding the failed Franklin Expedition of 1845-48. The sinister, frozen wastelands of the Arctic figure as the limit of both European humanity and rationality. In Simmons' novel, the traumatic encounter with cultural otherness conjures up visions of an implosion of colonial ambitions, as the crew members are gradually consumed by both the harsh environment and the ancient Inuit ice demon Tuunbaq and must confront the indifferent frozen wastes of a mythological, gothic North. Simmons' gothic North Pole constitutes an example of "extro-science fiction," situated beyond the limits of all knowledge.
\end{abstract}

Keywords: Anthropocene, contingency, ecogothic, modernity, posthumanism, speculative realism

The world of Cartesian extension is a world that acquires the independence of substance, a world that we can henceforth conceive of as indifferent to everything in it that corresponds to the concrete, organic connection that we forge with it - it is this glacial world that is revealed to the moderns, a world in which there is no longer any up or down, centre or 
periphery, nor anything else that might make of it a world designed for humans. (Meillassoux, After Finitude 115)

Modernity has resulted in an expansion of scientific knowledge, at the expense of traditional forms of knowing. Ever since the advent of what Quentin Meillassoux has called "Galileism," nature has been conceived of as both mathematizable and knowable in itself (After Finitude 113). Yet modern science also unveils the absence of any metaphysically grounded human meaning in the universe. At some point in the future, we may know what reality is, but in practice, modern, secularized knowledge lacks final certitude. Everything is contingent, for there is no metaphysical absolute left unscathed by scientific inquiry. The truth, the absent thingin-itself, lies beyond the bounds of access. Paradoxically, while natural science dethrones metaphysics and theology, holding out the possibility of accessing the real as it is, during the 18th century philosophy falls victim to what Meillassoux describes as the "Kantian catastrophe" (125). In Kant's philosophy, and by extension, all philosophies influenced by the Kantian turn, we cannot make intelligible statements about the world in itself. Philosophy, for Kant, must restrict itself to the phenomenal. The subject cannot ever access the noumenal. Reality eludes human understanding. We can only describe what we access. Hence, reality is bracketed. There is thus no way of escaping the correlation between subject and world, at least in a Kantian post-Enlightenment framework (Meillassoux, After Finitude 125-6). The thing-in-itself is inaccessible, even while natural science is perpetually unveiling the secrets of the world, and philosophy is left with nothing to say about the real as such. Continental philosophy reacts by recentering itself around the human subject. If the "Galilei event" constitutes a Copernican revolution, then Kant's philosophy composes a "Ptolemaic" counterrevolution in thought (128). It is against this anthropocentrism that all realism must affirm the mind-independent status of real objects. In this article, I argue that Dan Simmons' The Terror provides us with an example of science fiction that not only manages to affirm the independence and unpredictability of objects, but also offers multiple examples of the hyper-chaotic nature of reality. 


\section{Metaphor and Contingency}

Reality is far more complex than any language, for the latter is always already historically and culturally determined, not to mention the biological limitations of language users themselves. Vainly, the narrative of the Enlightenment would seek to bring us on a threshold, a point wherein words break, and immediate, sensual objects replace predicates. As opposed to the enumeration of delusions, we find in the real a place bereft of any theoretical safeguards. The glacial world about which Meillassoux speaks is itself a description, albeit in a negative sense: a more-than-discursive negative evaluation, a de-scription, a sundering of reality from symbolism. There exist layers of reality whose obscurity forecloses the possibility of access. Natural science promises the disenchantment of the world, while philosophy after Kant excludes the possibility of access to the thing-in-itself. In Kantianism, there is no way of escaping representation. "Correlationism," Meillassoux's neologism, denotes the broadly Kantian idea that we cannot speak of a world outside of our own experience. The unfortunate "Ptolemaic" turn of modern philosophy has resulted in our losing the "great outdoors." According to Meillassoux, this is precisely what has happened to Western thinking since the reactionary "Kantian catastrophe" (After Finitude 63). Outside of de-scriptive enumeration, there nonetheless emerges a world, or even a set of worlds, whose self-determinations erupt in the form of lawless objects. The triumph of reason exposes the inhuman contingency of the real world. Without a God we can believe in, there is no metaphysical certitude anymore. Far from representing a loss that we should mourn nostalgically, Meillassoux believes that the process of disenchantment engendered by science can help us attain a new absolute in the form of "hyper-chaos," the absolute absence of necessity in the universe which is nonetheless absolutely necessary (64). It is vital that necessity be completely absent from the world. Similar to those trapped on the ice, we cannot adhere to a purely textual practice. One cannot carve any old text onto pack ice, for such an abject trace will almost certainly be carried away into the double oblivion of emergence and disappearance. The floes care not for the flow of human meanings, emotions or desires. Modern science reveals the 
depths of our predicament. This revelation itself nonetheless provides a type of negative certainty: this universe we inhabit can produce anything, with the notable exception of a necessary existent: "contingency alone is necessary" (65).

The Arctic, both as concept, metaphor and environment, can teach us about the nature of reality, and for centuries, it has proven a source of both perplexity and wonder for European minds. As Eric G. Wilson has highlighted, "crystals, glaciers, and the poles form invitations to the uncanny, preludes to gnosis" (85). The question this assertion raises is, admittedly, a broad one, namely whether anybody is capable of surviving gnosis, defined as direct access to the scientifically proven contingency of reality. Is gnosis even possible, or is knowledge of the "glacial world" alluded to by Meillassoux but a mere component, a symptom of a radical destructuring that would undo any knower? As opposed to Kant, Meillassoux holds that "the stability of laws is consistent with their absolute contingency" (After Finitude 100). There is no need to deny the applicability of contingency to reality merely because, at this particular moment in time, the world exhibits a certain order which makes consciousness possible. The universe as such can be absolutely contingent and even chaotic, while nonetheless maintaining local islands of order. Reality in itself would be something remote, foreign to human knowledge. The most we can say is that there is absolutely no reason for something to either exist or not exist. If there is no God who provides a fundamental basis to the laws of the universe, there is absolutely no reason for anything to be or not to be. Chaos would be the absolute which remains after all metaphysics has been destroyed by science. As Meillassoux eloquently puts it,

If we look through the aperture which we have opened up onto the absolute, what we see there is a rather menacing power - something insensible, and capable of destroying both things and worlds, of bringing forth monstrous absurdities, yet also of never doing anything, of realizing every dream, but also every nightmare, of engendering random and frenetic transformations, or conversely, of producing a universe that remains motionless down to its ultimate recesses, like a cloud bearing the fiercest storms, then the eeriest bright spells, if only for an interval of disquieting calm. (After Finitude 64) 
In the absence of an all-encompassing necessity, no necessary object may exist. This raises the question whether metaphoric language can shield us from the prospect of a universe without any ultimate meaning, or whether metaphor merely deepens our post-metaphysical and post-religious predicament.

In the context of this article, we accept the figurative "invitation" of "the crystals, glaciers and the poles," and undertake an examination of allusion in relation to a fictional account of Arctic exploration. More specifically, using the example of Simmons' speculative fiction novel on the ill-fated Franklin Expedition of 1845-1848, I aim to shed light on the relation between realism, metaphor and meaninglessness, by looking into individuals' ability to survive access to eruptive, transgressive and aweinspiring sensual objects without succumbing to their sublimity, and the modes in which the contingency of reality can be represented. Wilson identifies three levels of the uncanny as manifested through the process of exploration. The "uncanny experience" begins with the familiar, then, heading through a liminal state "between the familiar and unfamiliar," it ends "in an utterly unfamiliar realm" (86). This differentiation remarkably echoes Meillassoux's distinction between three types of science-fiction worlds in his 2015 book, Science Fiction and Extro-Science Fiction. Type-1 worlds are "all the possible worlds that are irregular, but whose irregularity does not affect science or consciousness" (Meillassoux, Science Fiction 33). Such worlds differ slightly from our own, familiar settings, displaying few alterations or differences, although these certainly may have significant ramifications on both the characters and the plots of Type-1 narratives. Science as we know it is still possible in Type-1 worlds. Certain strange events, ruptures in causality, most certainly do occur, but their spasmodic nature would preclude the abandonment of science altogether. Type- 2 worlds, however, are more ambiguous: "these are the worlds whose irregularity is sufficient to abolish science, but not consciousness. They are thus genuine extro-science worlds" (Meillassoux, Science Fiction 36). In such fictional settings, human knowledge becomes utterly useless. Events are only obscurely intelligible, and no longer can daily life be led according to any consistent set of rules. In a Type- 2 world, rule-following behaviour succumbs to happenstance. Sudden 
causal eruptions make scientifically valid quantitative predictions all but impossible, yet some humans are still capable of somehow surviving the caprice of these impossible circumstances. Pragmatically, consciousness adapts through trial-and-error to cope with impossibility and impersonality, if only ever so precariously. The unreasonableness of reality in a Type-2 fictive world is not of a degree that would make any form of survival impossible. Transgression, in such a context, has become ecological, but relations are not so contingent as to preclude any form of adaptation on the part of agents and organisms. In a Type-2 fictive world, events occur of their own accord, without any discernible pattern. The weather changes in an instant, ice flows down from the pole, making a mockery of human ambitions, and expectations cannot be adjusted to such wholly unpredictable causality. But humans in the Type- 2 setting still manage to adapt and live together with such things. In a parody of Karl Popper's theory of "three worlds,"1 Meillassoux proceeds to introduce the notion of "Type-3 worlds." Such environments would not be conducive to any form of knowledge or consciousness: "the third type of universe devoid of necessary laws would no longer be a world: it would be a universe in which disorderly modifications are so frequent that ... the conditions of science as well as those of consciousness would be abolished" (Science Fiction 40). Whereas in Popper's model World 3.0 denotes an artificial, abstract social reality constructed through an evolutionary process of cultural selection, Meillassoux's Type-3 worlds are dehumanized, decultured, even destructured universes devoid of any form of calculable causality. The reality of such an ecology is so extreme as to foreclose the survival of any organism whatsoever. Transgression in a Type-3 world would belong to nothing in particular: every law would be broken, so much so that the mere possibility of any law or regularity would be eliminated. Type-3 worlds would be pure materialities about which one could not even speak, let alone comprehend, because nothing endowed with intelligence could exist in such an environment. It would be similar to a disembodied, formless world.

The example of the Franklin Expedition stands for the metaphor of the shipwreck and is relevant in examining how the "glacial world" described in Simmons' The Terror aligns with Meillassoux's triple model. 
Two British ships, the HMS Erebus and HMS Terror, set out in 1845 to find the legendary Northwest Passage, a shipping route that would have allowed British commerce access to lucrative Far Eastern markets. Both ships disappeared, but, to the present day, no conclusive evidence has been established about what exactly happened. Presumably, the crew members were stranded by unexpectedly thick ice and perished from harsh conditions. Neither of the ships, at the time Simmons wrote his novel, had been found. In 2014 and 2016, however, the wrecks of Erebus and Terror, respectively, were discovered (Moyer). The discovery of the wrecks dispelled some of the mystery of the events surrounding the disappearance, since the entire novel is built upon the intense speculation surrounding the missing ships. The shipwrecks that have been discovered display real properties amenable to retroactive scientific representations and reconstructions. The material remains can be a useful source of analysis in laboratories or display in museums for public access. However, the description can only get us so far into the interior of historical events. There is no way of reconstructing exactly what happened to the crew members of these ships, or the circumstances of their death. To cross from a mere science fiction world into the realm of "extro-science fiction" (XSF), is to lose one's bearings and deviate into an unfathomable distance from any recognizable reality. In extro-science fiction, "it seems that no order of any sort can be constituted and, therefore, no story can be told" (Meillassoux, Science Fiction 23). What matters is whether Simmons' fictive account renders a narrative. This point is sufficient to decide whether it is a Type-2 or Type-3 world. Extro-science fiction begins where both consciousness and knowledge end. Henceforth, there is a definitive criterion of what constitutes science fiction beyond the reach of science: such fiction lacks order, and no story may be told. In other words, the absence of both order and narrative in Simmons' The Terror proves its status as XSF. Inaccessibility is a salient theme in the novel. The fictionalized "diary" of Harry Goodsir, a medical doctor whose unidentified skeletal remains were recovered incidentally in 1869 and finally identified with the help of DNA testing in 2011, renders the Arctic obscurity as follows: "just north of the burial site rose Sheer Black Cliffs, as inaccessible as the Mountains of the Moon. ... Occasionally a fragment 
of Cold Moon would appear from between quickly moving clouds, but even this thin, pale moonlight was quickly lost in the snow and dark. Dear God, this is truly a Stygian bleakness" (Simmons 63). Darkness precludes the possibility of access, yet this actually serves to highlight the real, actual bleakness of the situation. By 1847, both ships had been stuck in ice because of unexpectedly harsh weather, shipwrecking the crew. Throughout the novel, we find allusive descriptions, such as a "phantasmagoric landscape," "vague, black featureless shapes," "frozen infernal circles of the dead below," "impossible tracks," "frighteningly malevolent and intelligent," "ebony circles," and "something beyond madness," to name but a few examples of allusion (91, 92, 130, 135, 259, 640).

\section{Eco-apocalypse and the Unredeemability of Reality}

In a strikingly Lovecraftian and parodic vein, Simmons offers the reader a perspective on the incomprehensible reality of an Inuit ice-demon known as Tuunbaq. The frozen white sea represents the place wherein colonialist white civilization meets its doom. Yet paradoxically, the advent of global commerce is also subject to the future destruction of this icebound world, the demon included. There is no redemptive content in Simmons' novel, which puts forward the idea that no form of human culture can adapt to the various historical accidents. Contingency, the historical accident of technologically advanced industrial civilization and its worldwide expansion, will spare nothing. Along with the ice, Inuit tradition and the local divinities are all slated to disappear because of the "kabloona sickness," the cosmic unbalancing of the world and ecology introduced by modernized, industrialized whites, or "kabloonas," in the Inuit language (710). The shipwrecking and "loss" of their crew through either sickness, starvation, murder or cultural assimilation is but the prelude to a shipwreck of cosmic proportions, an ecocide even more terrible than Tuunbaq, a terrifying prospect indeed, considering the horrendous image of the ice monster readers are confronted with during the course of the novel. As Siobhan Carroll emphasizes, the traumatic undoing and pollution of supposed "wild spaces" by the Anthropocene has contributed 
to a $21^{\text {st }}$-century aesthetic of ecological uncanniness ("The Terror" 67). Carroll argues for an ecoaesthetic reading of The Terror, highlighting the synchronic and even uchronic presence of the Anthropocene in the novel. The Terror places the reader outside of time, as knowledge of the sixth mass extinction was not present in scientific or lay circles during the $19^{\text {th }}$ century. When Simmons includes the phenomenon of global warming in the narrative, the $19^{\text {th }}$-century setting is instantly transported into a $21^{\text {st }}$ century discourse relating to environmental degradation:

When the Tuunbaq dies because of the kabloona sickness, the spirit governors- of-the-sky knew, its cold, white domain will begin to heat and melt and thaw. The white bears will have no ice for a home, so their cubs will die. The whales and walruses will have nowhere to feed. The birds will wheel in circles and cry to the Raven for help, their breeding grounds gone. This is the future they saw. (Simmons 710)

What is particularly interesting is the manner in which anthropogenic climate change is depicted here. The description is not direct, but it is rather the spirits ("spirit governors-of-the-sky") that observe a far distant future, inaccessible even to the most talented of Inuit shamans. None of the human characters, not even the Inuit, are aware of the catastrophic, apocalyptic future awaiting the Arctic. This temporality is, strictly speaking, ecstatic, and none of the protagonists can possibly be aware of what is occurring. Simmons provides the reader with what amounts to an impossibly large-scale perspective that cuts into the temporality of the novel's narrative.

Exploration is far from being politically neutral. Aside from increasing the stock of exploitable, economically viable knowledge, exploration is exposed, through the vision of the Arctic melting because of the man-made global warming as an imperialist process of worlddestruction that transforms the Inuit's homeland into a "godless landscape" degraded beyond recognition, populated by humans "who no longer perceive themselves as meaningfully enmeshed" in "ecological networks" (Carroll, "The Terror" 75). For Carroll, indigenous knowledge has a redemptive potential that is ignored by Erebus and Terror's British crew at their own peril because of the haughty pretensions pertaining to the cultural superiority of modern European knowledge. Indeed, the 
ambiguous figure of Captain Francis Crozier, second-in-command of the expedition, Catholic and Irish in a world dominated by Protestant English culture, also underlines the dual theme of imperialism and racism that permeates The Terror's plot. In one scene, Crozier recalls the experience of racist labelling, having been called a "black Irish nigger" by an arrogant English officer years prior to the events of The Terror (Simmons 123). Carroll's assertion that Simmons somehow gives "the key to the Tuunbaq's story" to the Inuit culture, in my view, fails to impact the novel's status as XSF. No human culture can redeem the end of the world. The ecocide that can only be seen by spirits or impossible, nonexistent God's eye views, being invisible to all human agents, is unredeemable, at least by human protagonists and cultures. There is no way to save a world heading for oblivion. A glacial world is one that is absolutely unresponsive to human concerns. The Terror is terrifying precisely to the extent that all forms of human knowledge, even those more adapted to the Arctic environment such as that of the indigenous Inuit, fail in the end. Hyperchaotic contingency offers no safety.

Tuunbaq is "pure terror itself" (Simmons 707). What Carroll's reading seems to miss is that nobody is capable of domesticating the sheer black monstrosity of contingency. While it is correct that after a certain point, the narrative switches from a Western to an Inuit cultural paradigm, none of these can actually bring chaos back under control. The possibility of bringing things back under control eludes the natives as well: the ecoapocalypse transcends human meaning. This is an event whose temporality overwhelms any human presence whatsoever. The privileging of one culture or anthropological paradigm over another merely serves to obscure the significance of the eco-apocalyptic exo-event described in The Terror. Identifying this event with human processes such as globalization, imperialism, or capitalism, fails to do justice to the ontological implications of what the phrase "terror" symbolizes. Realism, once initiated, cannot be stopped halfway. The advent of reality is excessive, something that bleeds into us from the outside, rendering language and culture alike passive receptacles of sheer, brute, cosmic causality. Created by the Spirit of the Sea in her jealousy of the two other primary elements, the Spirit of the Air and the Spirit of the Moon, Tuunbaq was originally a 
cosmic force, pure Chaos that threatened to undo the very fabric of the world but finally domesticated somewhat and imprisoned within a demonic body (706-7). One may argue that this hazard, or fundamental danger to existence is the undomesticatable demonic essence of lawless disordered formless reality in its becoming. The notion of universal contingency states that "everything is possible, anything can happen except something that is necessary" (Meillassoux, After Finitude 65). It may even be supposed that the process of ecocidal world-destruction, global warming as envisioned by the Inuit spirits forecasting the doom of the Arctic, is actually another manifestation of the infinite power of the same cosmic evil that Tuunbaq symbolizes. It makes sense to attribute the nameless, godless reality of evil to its immediate manifestations, be they kabloona invaders or Tuunbaq, but such predicates must not be confused with the reality of the thing-in-itself. Western modes of knowledge fail to explain Tuunbaq, but this does not mean that indigeneous modes of knowledge are immune to contingency, as Carroll assumes. The real is unmotivated by human intentions or culturally coded desires: contingency is utterly superior to social reality, even though both can coexist to a certain extent. Indigenous knowledge is better acclimatized to the Arctic, but an accident of history - global warming driven by industrialization will destroy this culture, too. What an excessively culturally-focused reading misses is the very real, cosmic dimension of a "terror" that "will not end" (Simmons 343). The strength of Simmons's narrative method lies in its uncannily effective rendition of the boundlessness of reality. No vantage point is safe from the blackened, "Stygian bleakness" of the real. As Catherine Lanone has noted in relation to the Franklin Expedition's cultural readings, expectations of progress can easily degenerate into "dehumanizing regression" (30). It is the ecological ramifications of this dehumanization and deracination that we must uncover, if we are to access the true depths of horror unleashed by Simmons' work. An ecogothic perspective, in this case, means a mode of inquiry attuned to the horrific aspects of a nature damaged beyond repair (Smith and Hughes 1-14).

The idea of evolutionary regression is a theme that, similar to that of unredeemability, permeates The Terror. These two topics complement each other. By the late stages of the expedition, it is a known historical 
fact that the desperate crew members engaged in acts of cannibalism. The entry date of the $20^{\text {th }}$ of August 1848 in Goodsir's diary, fictionalized by Simmons, recounts a "Feast of Human Flesh" celebrated by mutinous crew members (Simmons 654). Contingency results in Goodsir's having to face the choice between "becoming a Chef for Cannibals or being Maimed and Carved myself" (655). Once cultural refinement, religious sensibilities and metaphysical illusions disappear, raw flesh is all that is left. Confrontation with the inhospitability of glacial reality results in an almost mystical perversion, a transgression that dismembers the body of human culture. It is significant that the literal carving up of crew members occurs after the collapse of hierarchical relations between the captain and his crew. By this point, most of the commanding officers are all long dead, for the monster, Crozier realizes, has been deliberately intent upon figuratively "decapitating" the expedition. Crozier's reading of the "Book of Leviathan," that is, Thomas Hobbes' Leviathan (245-247), has great political and theological significance. In their days, Hobbes and Spinoza were widely derided as atheists, even Satanists (Mintz 58). The North Pole feeds the madness of the crew, that, by this stage, fetishize the mysterious ice demon as some kind of divinity, much to Crozier's displeasure. Crozier thus proceeds to organize a blasphemous mass centered around a passage from Hobbes' Leviathan with the aim of raising the morale of his crew. Too lengthy to quote in its entirety, the agnostic, even sacrilegious tone of the passage nevertheless stands out in the following sentences:

They have also ascribed Divinity, and built Temples to meer Accidents, and Qualities; such as are Time, Night, Day, Peace, Concord, Love, Contention, Vertue, Honour, Health, Rust, Fever, and the like; which when they are prayed for, or against, they prayed to, as if there were Ghosts of those names hanging over their heads, and letting fall, or withholding that Good, or Evill, for, or against which they prayed. They invoked also their own Wit, by the name of Muses; their own Ignorance, by the name of Fortune; their own Lust, by the name of Cupid; their own Rage, by the name of Furies; their own privy members by the name of Priapus; and attributed their pollutions, to Incubi and Succubae: insomuch as there was nothing which a Poet could introduce as a person in his Poem, which they did not make either a God or a Divel. (Hobbes 67-68) 
Here Hobbes gives voice to what may bedescribed as social constructivism in contemporary terms, namely the idea that religious concepts and even divine entities are cultural constructs, products of social evolution, illusions whose function is primarily to assist in maintaining social cohesion. Religious and spiritual concepts are fabrications of the mind. Humans, being social animals, need certain beliefs that enable them to adapt to circumstances. Religion is merely another method of storing social information, as well as reducing the cognitive stress of individuals. Illusions serve humans' survival, insofar as they allow them to personify impersonal forces, making the world more hospitable and amenable to their desires. However, Hobbes is already writing for a modern, enlightened audience, in whose eyes the plausibility of religious ideas has been eroded by both scientific and geographic discoveries. The advent of colonialism brought a new relativism into thinking about cultural phenomena, for the European colonizers could encounter cultures completely different from the Christian ones. Underneath all beliefs, Hobbes finds "meer Accidents." The accidental, the contingent, the chaotic, is what underlies the religious phenomenon. Religion is essentially a human cultural response to the rule of chaos in the realm of causality. Spirituality is risk-management.

\section{Modernity as the Shipwreck of the Human}

Once one has realized that one's most cherished beliefs are nothing more than social constructs, one may be left in a state of disillusionment similar to Captain Crozier's spiritual state. The epitome of the rationally- minded Occidental male, Crozier believes in nothing, apart perhaps from a vague notion of social integration stemming from his previous experiences in the Navy. His goal in reciting the Hobbes passage is to enlighten the crew and make them remember that belief is an instrument for survival, not a goal in itself. What matters is that the Book of Leviathan, for all its agnosticism and religious skepticism, still manages to furnish a functionalist model of the political body. We find in Crozier's self-described atheism a peculiar connection with exploration and seafaring as such. As distinct from his devout Irish grandmother, Crozier never believed in clairvoyance or 
Catholicism: "He realized that he also did not believe in God. He went to sea" (Simmons 344). Sacrilege and seafaring are intimately connected, a fact pointed out by philosopher Hans Blumenberg in his essay, Shipwreck with Spectator: "there is a frivolous, if not blasphemous, moment inherent in all human seafaring, on a par with an offense against the invulnerability of the earth" (10). Escaping from God means plunging into the waves, even if these waves are solidified ice floes. Where illumination is possible only through excessive allusiveness, the horrific thing-in-itself can be recalled in the form of a devious appendage of the Devil's Kingdom. As distinct from dry land, the sea is traditionally thought of as symbolizing the constancy of movement. It is certainly tempting to anthropomorphize any and all "accidents," as Hobbes refers to contingency, because such extrapolations make coping with the uncannily indifferent environment much simpler. The shipwreck, in Ancient Greek thought, is conceived of as the "legitimate" result of seafaring, for the place of the god-fearing human is supposed to be on solid ground, the ground of Being (10-1). Blumenberg sees in the sea journey a central metaphor whose content has nevertheless undergone a shift during the course of Western social evolution.

The Ancients perceived the sea journey in terms of self-discovery, whereas the Moderns have come to view exploration as being not distinct from other goal-directed instrumental actions that take us outside of ourselves. In the case of Montaigne, for instance, spectatorship is not a crime, even when it involves the observation of somebody else's shipwreck, for it creates the chance of enjoying one's own distance from the storms of life (17). During the Enlightenment, curiosity becomes ever more prominent in accounts of observation. Paradoxically, the advent of modern natural science has also made possible the realization of our own cosmic insignificance. The idea of the cosmic insignificance of human beings became widely popularized by major authors of the Enlightenment such as Voltaire and Diderot. Blumenberg summarizes this ontological thesis: "human history is a cosmically unnoticeable event" (38). This regression into insignificance is also evident in Simmons' reinterpretation of the Franklin Expedition. Two crew members in particular, the old steward John Bridgens and the younger officer Harry Peglar, sometime lovers and amateur philosophers, engage in a debate about Charles 
Darwin's theory of natural selection. Bridgens voices his belief that the ice-demon is an ancient creature far pre-existing the rise of mammals. Natural selection, Bridgens informs Peglar, involves "vast," "Lyellian amounts of time," while the monster's lifespan could be so immense that "our bones will be fossils before its will" (Simmons 370-1). PostDarwinian evolutionary theory gives neither comforting answers nor metaphysical solutions, for it continues to describe how life constructs itself and leaves its meaning open. The laws of evolution have no basis in morality. Knowledge of natural selection, in the case of the Franklin Expedition's crew, can only illuminate the precarity of their own existential situation and the decrepitude of human existence against the immensity of reality. Evolutionary deep time cannot be reintegrated into cultural intelligibility.

Is there an ethical stance one can nonetheless extract from the constancy of change, and furthermore, the inevitability of the submergence of homo sapiens amongst the waves of evolution? We too, as animals, are destined to become extinct. To evolve means, above all, to change. The probability, indeed, certainty of our own demise and extinction can lead us to a state of calm acceptance. As Blumenberg writes, "being becalmed is lethal to life" (64). Sages who attain to the sovereign serenity of acceptance emplace themselves in a state of passive receptivity. The Darwinian revelation of evolution's laws is inseparable from the realization that humans are also subject to the destructive power of selection. There is no certainty that humans will always be the dominant terrestrial vertebrates. The advent of new objects within a field of action invariably tends to produce fissions between prior forms, making involvement synonymous with formless, wasteful autophagy. Bridgens knows that natural selection, upon the icy plains, has resulted in the creation of a creature capable of eliminating human presence. Bridgens is a scientifically-minded individual, who keeps the possibility of evolutionary variation open by creating unthinkable exospecies. Readers know that Bridgens, lacking access to Inuit folklore, is not entirely correct in his characterization of Tuunbaq as an "animal." Nevertheless, the laws of Darwinism could apply to demons as well. Nothing is entirely certain apart from the inadequacy of modern, enlightened scientific knowledge in 
the inhospitable Arctic landscape. On the whole, cultural distinctions do not seem to matter terribly much in Simmons' Gothic vision. Why does it matter where we leave our fossils? Extinction and death are natural phenomena that may affect all species. Selection is a constant menace, comparable to the menace presented by the ice. After his chat about Darwinism with Peglar, Bridgens informs Goodsir of his intention to walk away from the struggle of life. Appalled but unsurprised, Goodsir questions the merits of such talk, but the wise old steward cannot be convinced otherwise: "I'm sorry, Doctor, I just have a strong desire to stroll" (Simmons 604). Then, leaving the camp, the Stoic sage falls asleep in the winter wind, collapsing into the abyss of death, disappearing along with the faint sunlight (608). Nighttime in the Arctic winter is the time of fossilized mineral dreams.

Extinction separates those crew members lucky enough to die from any further suffering, but their disappearance without a trace also precludes anything resembling a coherent documentation of this human misadventure. Nobody actually possesses Goodsir's diary. Its words, if indeed the surgeon ever led a diary documenting the voyage's events, have been lost to posteriority. The version we read in The Terror is a fictive rendition designed to simplify reader access to the spatially- and temporally distant narrative. Yet even Goodsir's fictionally constructed sentences break apart, collapsing into grammatically- and syntactically incoherent nonsense while poisoning himself so as to thereby posthumously murder his relentless, cannibal criminal crewmates: ,befre this EAT THESE MORTAL REMNAS OF DR HARRY D.S. GOOODSIRIFFF YO U WISSSH THE POISSSSN WITHINN THS BONES AND FELSH WIOL KILL YOOU ALSO TheMen at Re cm Thomnas, if they Find this Upon my and Ret" (674). Simmons' own authorial perspective is that of a callous God, who views all events with the same cold impartiality. As Carroll argues, the circumstances of the disappearance of the crew members of the Franklin Expedition "denied" the public "any insight into the explorer's characters at their moment of greatest trial" (Empire 62). This epistemological uncertainty presents a contagious threat to the British imperial body politic, for it leads to absolute regression and ethical degeneration. Such a possibility is 
underlined by Simmons too since he uses temporal obscurity to play with the description of multiple ethical positions. If Bridgens is a metaphor for the Stoic sage who calmly accepts death, then his antipode is Cornelius Hickey, one of the most evil members of the crew, who takes every chance he gets at every turn to commit a wide variety of infractions, crimes and sins. Yet Hickey is also the only protagonist who seems to transcend the human condition. Through the sheer, unspeakable purity of his evil character, Hickey becomes more than human, that is, a divinity. From a posthumanist perspective, "there is no stable human essence to allow a clear-cut distinction between what is human and what is not" (Bergthaller 85). An important thesis of Blumenberg is that humans are always in need of "guidance," yet this guidance is also "always far short of its own promises" (89). The promises of Western religion fall short of the crew member's expectations. Under extreme circumstances, ethical experimentation becomes the norm. Humans' theoretical perspective upon the world is always open to a fatal rupturing. This openness also means that they may become animals, gods, angels and demons alike. Hickey's final transformation, however, is not the product of mere delusion. An Irishman, like Crozier, Hickey chooses the path of evil, and actively seeks to transform himself into an embodiment of unadulterated malignance. $\mathrm{He}$ becomes "something nonhuman," his eyes showing "something beyond madness," "far beyond mere hatred" (Simmons 640). In his insanity, the figure of the sovereign criminal is unveiled as the inner monster of the human, residing within all but the most docile human beings as a latent malevolence. The state that Hickey has reached serves to underline the complexity of posthuman becomings. Transitioning to a more-than-human state by no means implies that such a transformation is for the better. While Bergthaller views Blumenberg's position as one that would rescue and rejuvenate metaphors (90), things are more complicated than they seem, for metaphors can also present themselves as symptoms of cultural decadence (Blumenberg 96). The decadence of Christian values and the failure of even Crozier's disenchanted modernist and utilitarian social functionalism leads to the uncovering of pure evil as well as purified ethical indifference. If Bridgens embodies the Stoic epitome of dying in tranquility while letting others live, Hickey represents the paradigm of 
making others die to gift himself with eternal life. Hickey is no longer a mere mortal; the criminally insane Irishman of poor background becomes "God" (Simmons 676). After consuming all of his deceased fellow mutineers, Hickey is left alone, seated upon a makeshift throne. Hickey waits for "the Age of Darkness" that would last for ten thousand years, blotting out the Sun and all divine light, the age of limitless demonic infestation when all that was formerly held sacred, nature included, shall be defiled, deformed and degenerated beyond recognition (678-9). Hickey's indifference to the deaths of all those around him leads to precisely the same result as that of Bridgens' ethically more inspired indifference: Hickey also experiences a state of "deep cosmic peace" (679). Pure good and plain evil both result in calming the nerves, concomitant with a harmony beyond any conventional morality. What else could this condition be, if not the state of "nonconceptuality" (Blumberg 99), the fulfillment of what one already was all along? After all, readers are informed that "Cornelius Hickey had no regrets about any part of his former mortal life. He had done what he had to do" (Simmons 679).

In the long run, presence itself can be extinguished by time. Barely any material traces of the crew were found. Most of the corpses were never recovered. Experience, both outside of and among the bergs, is a dark allusion to the fictional nature of existence itself. At the limit of thought, we come to doubt the integrity of concepts, including that of reality. Skepticism with regard to existence can be extended hyperbolically, resulting in the hysterical paroxysm of nonconceptual distancing. Impossibility could be inherent within not only science fictional, or even extro-science fiction worlds, but also in the case of our own world. The waves of history wash away human presence. Culture cannot immunize us against the brute force of causality. Simmons addresses the possibility of absolute non-realism when he states the following about the entire ordeal he has been chronicling: "it was as if they had never existed" (662). We think we knew something about somebody or some event, but every configuration is merely a set of relations among contingent temporal components that lack substantiality. The most horrific thing about things-in-themselves is the possibility of their emptiness. Blumenberg expresses the same anti-realist suspicion 
when he argues that "both progress and sinkings leave behind them the same peaceful surface" (59). If posthumanism contained any ethics, it would reside in the injunction to accept who and what we are. Within limitless acceptance, there is a mystical unity with the peaceful surface of indifferent extension, a harmony beyond categorizations or particularities, even if the pathways leading to peace are manifold, and the destination is the same for both good and evil paths. Acceptance is the only way to achieve union with the blank slate of inexistence. Being humans means being always open to the possibility of one's own disappearance.

\section{Conclusion: The Terror as Extro-Science Fiction}

To conclude, Simmons' work constitutes an "extro-science fiction" world. It is my contention that universal disorder, chaos and complete inexistence are all ontological possibilities which appear at a subliminal level in Simmons' novel, but also at the very center of the narrative. Therefore, it arguably illustrates a Type-2 XSF world, or even a Type-3 chaotically extra-scientific ecogothic wasteland. It is the failure of Inuit forms of knowledge, otherwise well adapted to the Arctic environment, in the face of global warming that militates for a completely extro-scientific viewpoint. Viability proves impossible even for those who have inhabited the Arctic for millennia, because the variations and fluctuations of nature do not spare even the strongest or most flexible animals. The human element too is destined to degenerate and disappear into the immensity of this inexistent, indifferent dead world, along with nature and the spirit realm. An important premise of Blumenberg's dynamic view of metaphorology is that even the most finely attuned metaphors, conceived of as cultural norms, only serve their protective compensatory purpose for an uncertain period of time. Once the protective cocoon of culture is abandoned, Stoic resignation or unspeakable evil are the sole ethical options that seem to remain. 


\section{Notes:}

${ }^{1}$ In Popper's usage, "World 1" denotes the realm of physical objects and events, "World 2" the realm of mental objects and thoughts, while "World 3" designates the area of what Popper calls, rather confusingly, "objective" reality, which is actually everything that can be called "intersubjective" or "social" reality, such as institutions and scientific knowledge.

\section{Works Cited}

Bergthaller, Hannes. "On Human Involution: Posthumanist Anthropology and the Question of Ecology in the Work of Hans Blumenberg and Niklas Luhmann." New German Critique 43. 2 (128) (2016): 83-104.

Blumenberg, Hans. Shipwreck with Spectator. Paradigm of a Metaphor for Existence. Trans. Steven Rendall. Cambridge: MIT Press, 1985.

Carroll, Siobhan. "The Terror and the Terroir: The Ecological Uncanny in New Weird Exploration Narratives." Paradoxa 28 (2016): 67-89.

---. An Empire of Air and Water. Uncolonizable Space in the British Imagination, 1750-1850. Philadelphia, PA: Uof Pennsylvania P, 2015.

Hobbes, Thomas. Leviathan: With Selected Variants from the Latin Edition of 1668. Ed. Edwin Curley. Indianapolis, IN: Hackett, 1994.

Lanone, Catherine. "Monsters on the Ice and Global Warming: from Mary Shelley and Sir John Franklin to Margaret Atwood and Dan Simmons." EcoGothic. Ed. Andrew Smith and William Hughes. Manchester: Manchester UP, 2013. 28-43.

Meillassoux, Quentin. Science Fiction and Extro-Science Fiction. Trans. Alyosha Edlebi. Minneapoliss, MN: Univocal, 2015.

---. After Finitude: An Essay on the Necessity of Contingency. Trans. Ray Brassier. New York: Continuum, 2008.

Mintz, Samuel I. The Hunting of Leviathan: Seventeenth-century Reactions to the Materialism and Moral Philosophy of Thomas Hobbes. Cambridge: Cambridge UP, 2010.

Moyer, Justin Wm. "HMS Erebus, Lost Ship whose Crew Resorted to Cannibalism, Found in Canadian Arctic.” The Washington Post 3 Oct. 2014. Web. 18 July 2018.

Popper, Karl. Objective Knowledge. An Evolutionary Approach. Oxford: Oxford UP, 1972.

Simmons, Dan, The Terror: A Novel. New York, NY: Little, 2007.

Smith, Andrew, and William Hughes. "Introduction: Defining the EcoGothic." EcoGothic. Ed. Andrew Smith and William Hughes. Manchester: Manchester UP, 2013. 1-14.

Wilson, Eric G. The Spiritual History of Ice. Romanticism, Ice, and the Imagination. New York: Palgrave Macmillan, 2003. 